CLINICAL STUDY

\title{
Serum adiponectin levels, insulin resistance, and lipid profile in children born small for gestational age are affected by the severity of growth retardation at birth
}

\author{
Eleni N Evagelidou, Vasileios I Giapros, Anna S Challa ${ }^{1}$, Dimitrios N Kiortsis ${ }^{2}$, Agathocles A Tsatsoulis ${ }^{3}$ \\ and Styliani K Andronikou \\ Neonatal Intensive Care Unit, ${ }^{1}$ Research Laboratory of Child Health Department, Medical School, ${ }^{2}$ Department of Physiology and ${ }^{3}$ Department of \\ Endocrinology, University of Ioannina, Ioannina, Greece \\ (Correspondence should be addressed to V I Giapros who is now at University Hospital of Ioannina, PO Box 1186, Ioannina 451 10, Greece; Email: \\ vgiapros@cc.uoi.gr)
}

\begin{abstract}
Objective: Insulin resistance has been linked to intrauterine growth retardation (IUGR); adiponectin is a protein with insulin-sensitizing properties. This study was designed to test whether being born small for gestational age (SGA) has an effect on blood levels of adiponectin and leptin, insulin resistance parameters, and lipid profile in pre-puberty, taking into consideration the severity of IUGR.

Methods: Serum levels of adiponectin, leptin, total cholesterol (t-CHOL), high density lipoprotein (HDL)cholesterol, low density lipoprotein (LDL)-cholesterol, triglycerides, apolipoproteins A-1 (Apo A-1), Apo B and Apo E, lipoprotein(a) (Lp(a)), fasting glucose, and insulin (Ins), the homeostasis model assessment insulin resistance index (HOMA-IR) and anthropometric indices were evaluated in 70 children aged 6-8 years, born appropriate for gestational age (AGA; $n=35)$ and SGA $(n=35)$, matched for age, gender, height, and BMI. SGA children were divided into two subgroups according to the severity of IUGR: SGA < 3rd percentile $(n=20)$, and SGA 3rd-10th percentile $(n=15)$. They were also subdivided in two subgroups, those with $(n=25)$ and those without $(n=10)$ catch-up growth, considering their actual height corrected for mid-parental height.

Results: SGA children had higher Ins and HOMA-IR than AGA children (Ins, $42 \pm 23$ vs $32 \pm$ $11 \mathrm{pmol} / \mathrm{l}$; HOMA-IR, $1.30 \pm 0.8$ vs $0.92 \pm 0.3 ; P<0.05)$. No significant difference in serum leptin was found between the SGA and the AGA groups but adiponectin showed a trend to be higher in SGA children $(13.6 \pm 5.7$ vs $10.8 \pm 5.9 \mu \mathrm{g} / \mathrm{ml}$ respectively). SGA children without catch-up growth had higher adiponectin $(15.6 \pm 8.5 \mu \mathrm{g} / \mathrm{ml}, P<0.05)$ than AGA children. Among the SGA children, the subgroup $<3$ rd percentile had higher Lp(a) than the subgroup 3rd-10th percentile $(P<0.05)$. An independent positive correlation between adiponectin and $\operatorname{Lp}(\mathrm{a})$ was observed in SGA children $(R=0.59, P<0.01)$.

Conclusion: SGA children, although more insulin resistant, had similar or higher adiponectin levels than matched AGA children in pre-puberty. The severity of IUGR appears to affect their metabolic profile during childhood.
\end{abstract}

European Journal of Endocrinology 156 271-277

\section{Introduction}

Adiponectin is a protein consisting of 247 amino acids, produced by the most abundant gene transcript-1 (apM1) expressed in human adipose tissue $(1,2)$. This protein has been implicated in the pathophysiology of obesity-related insulin resistance, glucose intolerance, insulin-mediated lipoprotein metabolism, atherosclerosis, and coronary heart disease (1). The physiological role of adiponectin is yet to be completely determined, but its reduced expression and hypoadiponectinemia have been associated with insulin resistance in animal and human studies (1).
Low birth weight has also been related with increased risk for developing the metabolic syndrome in adulthood $(3,4)$. Some researchers have proposed that this association is genetically mediated (5), while others have postulated that it is the result of fetal adaptation to an adverse intrauterine environment (3); the environment of the embryos may program alterations in their metabolic profile that will be expressed later in life $(3,6)$.

Only limited and controversial information is available about circulating adiponectin levels in pre-pubertal children born small for gestational age (SGA) (7-9). The two studies that investigated adiponectin levels in prepuberty $(7,8)$ enrolled short SGA-born children who 
were being monitored in outpatient endocrinology departments for short stature. It is known that most SGA born children 'catch-up' with the normal growth range postnatally with only a minority (10-20\%) remaining short in childhood and adult life (10). The present study was designed to enroll a representative sample of SGA children born in a regional hospital and not only those with short stature.

Associations between adiponectin and blood lipids have been demonstrated in adults and adolescents (11, 12), but limited data have been published on blood lipids and their relation to adiponectin in SGA born children. A few studies showed mild disturbances of lipids in this group $(13,14)$, while others failed to reveal any lipid abnormality $(8,15)$. Lipoprotein(a) $(\operatorname{Lp}(\mathrm{a}))$ is an independent predictor of coronary disease that has been measured only in one study in SGA children (16). Although levels of $\mathrm{Lp}(\mathrm{a})$ are to a high degree genetically determined, significant associations with other lipoproteins have been demonstrated in children $(16,17)$ and its relation to other metabolic parameters in SGA children would be of interest.

SGA children are usually investigated as a group without taking into consideration the severity of their intrauterine growth retardation (IUGR). Pooling the findings may hide differences of clinical significance between more and less severely growth retarded children. This study was designed to investigate adiponectin, insulin sensitivity, leptin, the lipid profile, and anthropometric markers in children born appropriate for gestational age (AGA) and SGA children, taking into consideration also the severity of IUGR.

\section{Subjects and methods}

The study included 70 pre-pubertal children aged 6-8 years, born SGA $(n=35)$ or AGA $(n=35)$ during an 18-month period (January 1996-June 1997) at the University Hospital of Ioannina, Greece, and living in the same geographical area in Northwestern Greece. This hospital hosts the majority $(>85 \%)$ of births in a well-defined geographical area. The anthropometric measures at birth were obtained retrospectively by a chart review of all neonates born in the hospital during the 18-month period. The AGA children were matched with the SGA subjects according to age, gender, body weight (BW), body height (BH), and body mass index (BMI). All the subjects were selected to be non-obese, with BMI lower than the 85th percentile based on growth charts specific for age and sex for Greek children. The study was carried out after written consent was obtained from a parent of each child. The study protocol was approved by the Research Ethics Committee of Ioannina University Hospital.

SGA was defined as a birth weight less than the 10th percentile for the gestational age (GA) based on growth charts specific for age and sex for Greek children. The
SGA children were divided in two subgroups based on the severity of IUGR. The first SGA subgroup comprised children with birth weight below the 3rd percentile $(n=20)$ and the second subgroup children with birth weight between the 3rd and the 10th percentiles $(n=15)$. AGA was defined as birth weight, crown-heel length, and head circumference (HC) between the 10th and the 90th percentiles for the GA. Birth weight SDS scores for all study groups were calculated as SDS $=(x$-average $x) /$ S.D. where $x$ is the actual weight; $x$-average, the mean weight for gestational age and sex, and S.D., the standard deviation of the mean.

The children were evaluated at an age of between 6 and 8 years. Skinfold thickness (SFT) in the biceps, triceps, subscapular and suprailiac regions, and BMI were used as obesity parameters (18). BMI was calculated according to the formula: weight $(\mathrm{kg}) /$ height $(\mathrm{m})^{2}$ and BMI SDS scores were calculated. BW, BH, HC, SFT, and waist circumference (WC) were determined with techniques previously described (19). To estimate the effect of catch-up growth, the SGA children were reclassified into two subgroups according to their corrected height SDS (= actual height SDS - mid-parental height SDS) (mid-parental height = father's height $+($ mother's height +13$) / 2$ for boys, and mother's height + (father's height -13 )/2 for girls). Group A $(n=10)$ comprised those with a corrected height of less than 0 SDS, and group B $(n=25)$ those with a corrected height of equal to or greater than 0 SDS. Pubertal stage was assessed according to the criteria of Tanner for breast development in girls and genital development in boys.

\section{Hormone and biochemical assays}

Venous blood samples for laboratory analysis were collected between 0700 and $0800 \mathrm{~h}$, after 12-h overnight fasting. Serum adiponectin levels were measured by the Elisa method using the kit of Phoenix Pharmaceuticals Inc, Belmont, CA, USA (EK-ADI-01). The sensitivity of the adiponectin assay was $0.40 \mu \mathrm{g} / \mathrm{ml}$. The intra-and interassay coefficients of variation (CVs) were $<10$ and $<15 \%$ respectively. Serum leptin levels were measured by the Elisa method using the kit of BioVendor Laboratory Medicine Inc, Modrice, Czech Republic. The sensitivity of the leptin assay was $0.50 \mathrm{ng} / \mathrm{ml}$. The intra- and interassay $\mathrm{CV}$ values were 5 and $10 \%$ respectively. Serum total cholesterol (t-CHOL), triglycerides (TRG), HDL-cholesterol (HDLC), Lp(a) and apolipoproteins A-1 (Apo A-1), B (Apo B), and $\mathrm{E}$ (Apo E) were determined using standardized techniques described previously (20). Serum LDLcholesterol (LDL-C) was calculated using the Friedewald-Fredrickson formula: LDL-C $=\mathrm{t}-\mathrm{CHOL}-(\mathrm{HDL}-\mathrm{C}+$ TRG/2.2) (provided that triglycerides levels were lower than $400 \mathrm{mg} / \mathrm{dl}$ ) (21). Fasting plasma insulin level (Ins) was determined using an immunoenzymatic method (analyzer AXSYM, Abbott) and fasting glucose (Glc) concentration by the glucose oxidase method. Fasting 
Ins, the fasting Glc/Ins ratio and the homeostasis assessment model for insulin resistance (HOMA-IR $=$ fasting Ins $(\mathrm{mU} / \mathrm{l}) \times$ fasting Glc $(\mathrm{mmol} / \mathrm{l}) / 22.5)$ were chosen as measures of insulin sensitivity (22).

\section{Statistical analysis}

A sample size of 70 children was calculated to be adequate for detecting a difference of $25 \%$ in serum adiponectin between the AGA and SGA groups with a power $>80 \%$ at a significance level of $5 \%$. The calculation of the sample size was based on the adiponectin values (mean and s.D.) of the SGA study group, and on already published adiponectin values in children (23). The data were analyzed by one-way ANOVA, using Fisher's protected least significant difference test for comparing the means of the study groups pairwise. The Mann-Whitney U-test was used for comparison between abnormally distributed data. Results are reported as the mean \pm s.D. and ranges (minimum and maximum values). Multiple regression and forward stepwise regression analyses were also used to correlate adiponectin values and the other tested variables. After ascertaining that some variables were not normally distributed, logarithmic transformation was made. Statistical analyses were performed using the Stat View software package of SAS Institute, Inc., Cary, NC, Differences were considered statistically significant at $P$-value $<0.05$.

\section{Results}

On retrospective analysis of the hospital neonatal case notes, 68 children were identified as born SGA during the 18-month period. Forty-five of the sixty-eight were selected to participate in the study based on birth date, with every third SGA child being excluded chronologically. A further ten children were eliminated; for two the parents did not give consent, for three their contact details were not found and five were excluded because of $\mathrm{BMI}>85$ th percentile. The remaining 35 children were enrolled in the study. The perinatal characteristics of the non-participants (birth weight, gestational age, sex, mode of delivery) and of their mothers (age, parity, weight gain during pregnancy, pathology of gestation, socioeconomic status) did not differ from those of the children who participated to the study. The 35 matched controls were identified from among 150 AGA children born in the hospital during the same period who were initially contacted. Risk factors for IUGR were detected in 19 of the 35 SGA born children, with hypertensive disease of pregnancy being the most common (11/19 cases) following by placental insufficiency (4/19) and low maternal weight gain during pregnancy (4/19).

The anthropometric indices of the subjects at birth and at the time of the study are depicted in Table 1. At the time of the study there were no significant differences in mean age, BW, BH, BMI, and BMI SDS between the AGA and SGA groups, and all the children were at Tanner stage I. No statistical differences were found between the groups in SFT, but the subgroup SGA $<3$ rd percentile had significantly lower WC than the control AGA group $(P<0.05)$.

Table 2 shows the serum levels of adiponectin and leptin, and the insulin resistance parameters in the two groups of children at the pre-pubertal stage. No significant differences in levels of leptin were found between the SGA and the AGA groups, but adiponectin

Table 1 Anthropomorphic variables at birth and at the time of study in appropriate for gestational age (AGA) and small for gestational age (SGA) groups of pre-pubertal children.

\begin{tabular}{|c|c|c|c|c|c|}
\hline & AGA $(n=35)$ & SGA $(n=35)$ & $\begin{array}{c}\text { SGA 3rd-10th } \\
\text { percentile }(n=15)\end{array}$ & $\begin{array}{c}\text { SGA }<\text { 3rd percentile } \\
(n=20)\end{array}$ & $P$ value \\
\hline \multicolumn{6}{|l|}{ At birth } \\
\hline Gestational age (weeks) & $37.9 \pm 1.4$ & $37.0 \pm 1.3$ & $36.8 \pm 1.4$ & $37.1 \pm 1.7^{*}$ & NS \\
\hline Gender (male) & 20 & 20 & 9 & 11 & NS \\
\hline Birth weight $(\mathrm{g})$ & $3385 \pm 380$ & $1885 \pm 497^{\star}$ & $1990 \pm 448^{*}$ & $1755 \pm 426^{*}$ & $<0.001^{*}$ \\
\hline Birth length (cm) & $51.0 \pm 2$ & $44.5 \pm 4.7^{\star}$ & $45.4 \pm 4.3^{*}$ & $42.7 \pm 5.1^{*}$ & $<0.001^{*}$ \\
\hline Head circumference $(\mathrm{cm})$ & $34.8 \pm 1.3$ & $31 \pm 2.8^{*}$ & $31 \pm 2.7^{*}$ & $31 \pm 2.9^{*}$ & $<0.001^{*}$ \\
\hline \multicolumn{6}{|l|}{ At the time of study } \\
\hline Age (years) & $6.89 \pm 1.4$ & $6.92 \pm 1.2$ & $6.94 \pm 1.7$ & $6.89 \pm 2.2$ & NS \\
\hline Body weight (kg) & $26.1 \pm 6.2$ & $25.6 \pm 6.1$ & $25.8 \pm 6.6$ & $24.6 \pm 6.7$ & NS \\
\hline Body height $(\mathrm{cm})$ & $119 \pm 8.9$ & $118.3 \pm 9.3$ & $119.2 \pm 8.9$ & $117.9 \pm 8.1$ & NS \\
\hline Head circumference $(\mathrm{cm})$ & $50.9 \pm 1.2$ & $50.4 \pm 2.1$ & $50.4 \pm 1.9$ & $50.6 \pm 2.2$ & NS \\
\hline Waist circumference $(\mathrm{cm})$ & $60.9 \pm 7.7$ & $59.1 \pm 9.6$ & $59.7 \pm 10.2$ & $58.4 \pm 8.8^{\dagger}$ & $<0.05^{\dagger}$ \\
\hline BMI $\left(\mathrm{kg} / \mathrm{m}^{2}\right)$ & $18.5 \pm 2.1$ & $17.7 \pm 2.6$ & $18.2 \pm 2.5$ & $17.5 \pm 2.9$ & NS \\
\hline BMI-SDS & $0.18 \pm 0.48$ & $0.17 \pm 0.52$ & $0.18 \pm 0.52$ & $0.13 \pm 0.60$ & NS \\
\hline $\mathrm{SFT}^{\mathrm{a}}$-biceps (mm) & $7.4 \pm 2.0$ & $7.1 \pm 2.4$ & $7.2 \pm 2.7$ & $6.9 \pm 2.0$ & NS \\
\hline SFT-triceps (mm) & $10.1 \pm 2.7$ & $9.0 \pm 3.4$ & $9.3 \pm 3.5$ & $8.9 \pm 3.7$ & NS \\
\hline SFT-subcapular (mm) & $8.8 \pm 2.6$ & $8.6 \pm 2.9$ & $9.1 \pm 2.8$ & $8.4 \pm 3.1$ & NS \\
\hline SFT-suprailiac (mm) & $9.8 \pm 2.7$ & $9.4 \pm 3.4$ & $9.7 \pm 3.9$ & $8.8 \pm 3.0$ & NS \\
\hline
\end{tabular}

Values are means \pm S.D. Significances from pairwise comparisons for all groups are shown in the right column and they are as follows: ${ }^{\star} P<0.001$ all $S G A$ groups vs AGA for characteristics at birth, ${ }^{\dagger} P<0.05 \mathrm{SGA}<3$ rd vs AGA for WC.

aSFT, skinfold thickness. 
Table 2 Blood glucose (Glc) and insulin (Ins) levels, homeostasis model assessment (HOMA) index, and leptin and adiponectin levels at the time of the examination in children of pre-pubertal age born appropriate for gestational age (AGA) and small for gestational age (SGA).

\begin{tabular}{|c|c|c|c|c|c|c|}
\hline Study group & $\begin{array}{c}\text { Glc }(\mathrm{mmol} / \mathrm{l}) \\
\text { mean } \pm \text { s.D. } \\
(\text { ranges })\end{array}$ & $\begin{array}{l}\text { Ins }(\mathrm{pmol} / \mathrm{l}) \\
\text { mean } \pm \text { s.d. } \\
\quad(\text { ranges })\end{array}$ & $\begin{array}{c}\text { Glc/Ins ratio } \\
\text { mean } \pm \text { s.D. } \\
\text { (ranges) }\end{array}$ & $\begin{array}{l}\text { HOMA-IR } \\
\text { mean } \pm \text { S.D. } \\
\text { (ranges) }\end{array}$ & $\begin{array}{c}\text { Adiponectin } \\
(\mu \mathrm{g} / \mathrm{ml}) \text { mean } \pm \text { s.D. } \\
\text { (ranges) }\end{array}$ & $\begin{array}{c}\text { Leptin }(\mathrm{ng} / \mathrm{ml}) \\
\text { mean } \pm \text { s.D. } \\
\text { (ranges) }\end{array}$ \\
\hline AGA $(n=35)$ & $\begin{array}{r}4.66 \pm 0.38 \\
(3.9-5.5)\end{array}$ & $\begin{array}{c}32.32 \pm 10.89 \\
(8.9-49.4)\end{array}$ & $\begin{array}{r}23 \pm 10.5 \\
(8.4-63)\end{array}$ & $\begin{array}{c}0.92 \pm 0.32 \\
(0.18-1.65)\end{array}$ & $\begin{array}{l}10.8 \pm 5.9 \\
(3.6-18.9)\end{array}$ & $\begin{array}{l}9.1 \pm 5.3 \\
(2.8-26.4)\end{array}$ \\
\hline SGA $(n=35)$ & $\begin{array}{r}4.5 \pm 0.55 \\
(3.1-5.7)\end{array}$ & $\begin{array}{r}42.3 \pm 23.6^{*} \\
(13.8-110)\end{array}$ & $\begin{array}{l}17.2 \pm 8.8 \\
(6.5-39.5)\end{array}$ & $\begin{array}{l}1.30 \pm 0.8^{\star} \\
(0.28-4.08)\end{array}$ & $\begin{array}{r}13.6 \pm 5.7^{\dagger^{\prime}} \\
(3.6-21.5)\end{array}$ & $\begin{array}{c}11.2 \pm 8.9 \\
(3.2-35)\end{array}$ \\
\hline $\begin{array}{l}\text { SGA 3rd-10th percentile } \\
(n=15)\end{array}$ & $\begin{array}{r}4.86 \pm 0.27 \\
(4.1-5.1)\end{array}$ & $\begin{array}{c}43.8 \pm 19.2 \\
(13.8-73.6)\end{array}$ & $\begin{array}{c}16.6 \pm 9.1 \\
(8-39.5)\end{array}$ & $\begin{array}{c}1.33 \pm 0.23 \\
(0.39-2.24)\end{array}$ & $\begin{array}{c}12.6 \pm 6.8 \\
(3.6-19.5)\end{array}$ & $\begin{array}{r}13.4 \pm 9.2 \\
(3.2-35)\end{array}$ \\
\hline SGA $<3$ rd percentile $(n=20)$ & $\begin{array}{r}4.12 \pm 0.54^{\star} \\
(3.10-5.7)\end{array}$ & $\begin{array}{c}42.2 \pm 26.1 \\
(13.9-110)\end{array}$ & $\begin{array}{r}17.7 \pm 7.8 \\
(6.5-31)\end{array}$ & $\begin{array}{l}1.27 \pm 1.1 \\
(0.28-4.08)\end{array}$ & $\begin{array}{r}14.3 \pm 5.2^{*} \\
(9.5-21.5)\end{array}$ & $\begin{array}{l}10.3 \pm 6.9 \\
(3.3-25.5)\end{array}$ \\
\hline
\end{tabular}

Significances from pairwise comparisons for all groups are as follows: ${ }^{*} P<0.05$ SGA vs AGA for Ins and HOMA-IR, SGA $<3$ rd percentile vs. AGA for Glc, $\mathrm{SGA}<3$ rd percentile vs. AGA for adiponectin; ${ }^{\dagger} P=0.08$ for adiponectin $S G A$ vs $A G A$.

showed a trend to be higher in the SGA than in the AGA children $(P=0.08)$. In the subgroup of $\mathrm{SGA}<3 \mathrm{rd}$ percentile levels of adiponectin remained higher than AGA group after adjustment for differences in WC $(P<0.05)$. Concerning the insulin resistance parameters, the SGA group had significantly higher values of fasting Ins $(P<0.05)$ and HOMA-IR $(P<0.05)$ than the AGA group. The subgroup SGA $<3$ rd percentile had lower fasting Glc values than the AGA group $(P<0.05)$.

As shown in Table 3, no significant differences were observed in the serum t-CHOL, LDL-C, TRG, Apo A-1, Apo-B, Apo-E, Lp(a), and Apo B/Apo A-1 ratio between the SGA group and the AGA controls. However, within the SGA group, Lp(a) levels were significantly higher in the subgroup $S G A<3$ rd percentile than in the subgroup SGA 3rd-10th percentile $(P<0.05)$.

Further analysis was made according to catch-up growth between SGA subgroups A $(n=10)$ and B $(n=25)$. The two groups did not differ for age or sex. No differences were found in insulin resistance indices between these two subgroups. The mean values in subgroups A and B respectively were for: Ins (pmol/l) $43.6 \pm 21$ and $39 \pm 16$; Glc/Ins, $16 \pm 6.5$ and $19.6 \pm 11$ HOMA-IR $1.33 \pm 0.77$ and 1.15 \pm 0.67 . Adiponectin levels $(\mu \mathrm{g} / \mathrm{ml})$ in subgroups $A$ and $B$ respectively were $15.6 \pm 8.5$ and $12.4 \pm 6.6$, and leptin levels $(\mathrm{ng} / \mathrm{ml})$ were $7.2 \pm 5.1$ and $12.9 \pm 12$, and the differences were not significant. However, when compared with the AGA group, adiponectin values were significantly higher in subgroup A (SGA without catch-up growth; $P<0.05$ ) but not in subgroup B (SGA with catch-up growth). No significant differences were found in the levels of blood lipids between the two subgroups of SGA children.

\section{Multiple regression analysis}

Adiponectin was regarded as dependent factor and anthropometrics at birth and at the time of the study, insulin resistance indices, leptin, and levels of lipids were analyzed as independent variables. All the factors were first examined by simple regression and those which showed a significant relation to adiponectin were subsequently entered to a multiple regression model. These factors were BW, BH, BMI, and Lp(a) levels in the SGA group and BMI and Glc/Ins ratio in the AGA group. A positive independent association was observed only between adiponectin and Lp(a) levels in SGA children $(t=2.92, R=0.59, P<0.01)$. No independent relation was found in the AGA children between adiponectin and any of the other factors. Similar results in multiple and stepwise regressions were obtained when the factors were examined irrespective of their relation to adiponectin in the simple regression model. To avoid the 'colinearity' effect, factors that showed a close relation each other (i.e., BMI and BW, Ins and Glc/Ins etc.,) were entered separately into the model.

\section{Discussion}

In this study, higher insulin levels and HOMA-IR values were observed in the SGA group than in the matched AGA group. Several studies in adults and adolescents have shown an inverse relationship between adiponectin levels and insulin resistance (24-26). According to these earlier studies (24-26), the higher insulin and HOMA-IR levels observed in the children born SGA would be expected to be accompanied by reduced adiponectin levels compared with the controls. However, this was not so, and the adiponectin levels of the children born SGA were similar to or even higher than those of the AGA group.

Information on adiponectin levels in pre-pubertal children born SGA is limited $(7,8)$. Lopez-Bermejo et al. reported no differences in adiponectin levels between children born AGA and SGA attending an Outpatient Endocrinology Clinic for short stature (8). However, in agreement with the results of the present study, the adiponectin levels were shown to be higher in the SGA children after adjusting for sex, age, and BMI and also after accounting for insulin resistance in a general linear model of comparison (8).

In contrast to the results of the present study, Cianfarani et al. found lower adiponectin levels in SGA 


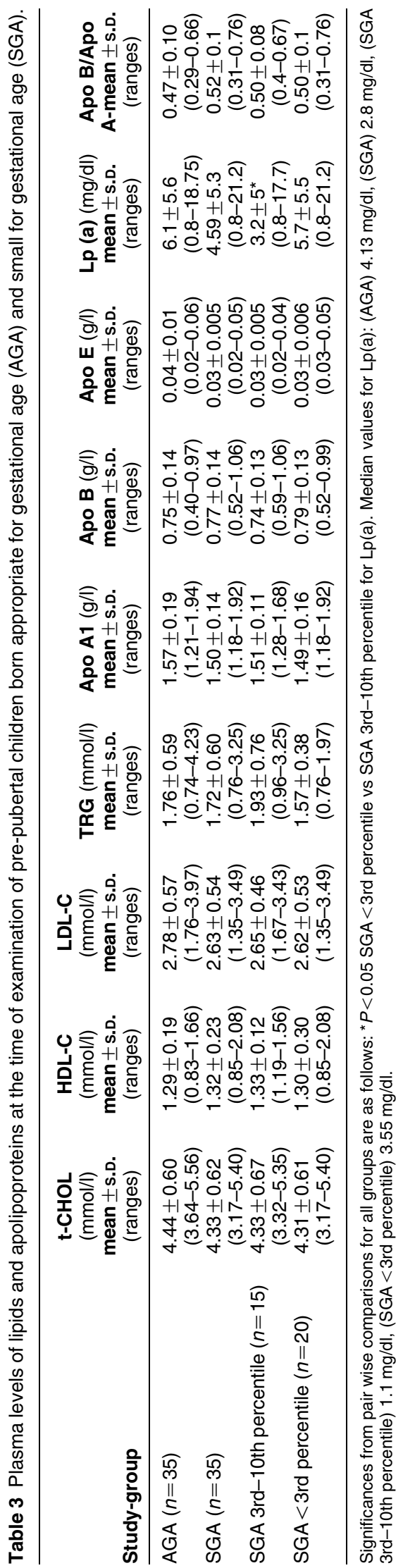

children attending an outpatient clinic for short stature than in short or obese AGA children (7). There are certain differences between the two studies. In the present study, a representative sample of SGA children recruited from birth charts was examined, and not only short SGA children, who account for only $10-20 \%$ of the total SGA born children (10). The controls in the Cianfarani study were either short or obese children and were significantly older than the respective SGA children. They also had an age range much broader than the children in the present study. These differences may have led to different findings in adiponectin values between the two studies, and when the SGA children in the present study were classified according to catch-up growth, increased adiponectin was observed in SGA children without catch-up growth, in agreement with the findings of Cianfarani et al. in short SGA children.

A recent large study in young adults (27) has shown that adiponectin levels are marginally higher in subjects born AGA compared with those born SGA (13.2 \pm 6 vs $12.6 \pm 7 \mu \mathrm{g} / \mathrm{ml}$ ), with a U-shape relationship between adiponectin and insulin resistance indices in the SGA, but not in the AGA group. This observation implies that some young adults born SGA are insulin-resistant despite relatively high levels of adiponectin, a finding observed also in some of the children in the present study. The authors interpret this as a defect in the insulin sensitizing action of adiponectin in SGA born adults.

It could be speculated that there is a period during the development during which SGA children exhibit insulin resistance combined with relatively raised adiponectin levels. Increase in the adiponectin level may be seen as an adaptation mechanism at this time, before a decline of this protein takes place later in life. It is possible that other metabolic, genetic, or inflammatory factors may also be related with the relatively high adiponectin levels observed in the SGA children in this study.

The links between IUGR and later metabolic disturbances, such as increased insulin resistance observed in this study, have not been fully elucidated. It has been speculated that intrauterine malnutrition could lead to decreased $\beta$-cell mass, and insulin resistance is intended to divert inadequate glucose resources to essential organs (brain and heart) at the expense of muscle (3). Another hypothesis involves a primarily peripheral reduced insulin sensitivity in utero, which allows a redistribution of nutrients, leading to eventual $\beta$-cell exhaustion (28). According to the 'catch-up growth' hypothesis (29), the crucial time for the development of long-term consequences is early postnatal life. Recent studies have shown that catch-up growth, especially in children born with a small birth weight, may cause long-term metabolic disturbances through mechanisms as yet unknown (29-31). In order to investigate whether catch-up growth affects the metabolic profile in pre-pubertal SGA children, the SGA children in the present study were subdivided into two subgroups according to their corrected height. The children 
without catch-up growth had higher adiponectin levels than AGA children, in accordance with the findings of previous studies $(7,8)$. Cianfarani et al. (7) estimated catch-up growth by calculating the corrected height, while Lopez-Bermejo et al. (8) by considering the BMI SDS, and both reported higher adiponectin levels in SGA groups not experiencing catch-up growth.

Reported data have shown that SGA children tend to develop lower lean body mass than those born AGA, which may contribute to differential metabolic functioning $(32,33)$. Although the two study groups of SGA and AGA children were matched for height, BW, and BMI and had similar SFT and WC, subtle differences in body fat content or fat distribution cannot be ruled out. The measurement of BMI, WC, and skinfolds are regarded as a reliable estimator of body composition although a dual-energy X-ray absorptiometry analysis is reported to be more precise (34). Minor differences in fat content or distribution between the two groups may have an impact on insulin resistance indices and adipokine levels. Irrespective of the factors that contributed to the higher insulin resistance indices observed in the prepubertal children born SGA, it appears that the somewhat higher circulating levels of adiponectin in this group cannot overcome the increased insulin resistance. The lower glucose levels observed in SGA $<3$ rd percentile subgroup may be the result of subgroup analysis and small sample size and not an indication of improved insulin sensitivity in this subgroup because all the insulin resistance parameters were similarly affected in both SGA subgroups.

The relationship between low birth weight and blood lipids has scarcely been investigated in childhood (13-16). Thenola et al. (14) reported that SGA children at the age of 12 years had the levels of total cholesterol in the high normal range, although no significant differences were found compared with AGA children. Cianfarani et al. observed that SGA children without catch-up growth had significantly higher cholesterol levels than AGA children, but in a study comprising only short children (13). Decsi et al. (15) and Pulzer et al. (16) found no difference in lipid profile in 10- and 15-year-old children respectively, except in $\operatorname{Lp}(\mathrm{a})$, which was measured in the latter study and found to be higher in SGA than AGA adolescents. In the present study, no differences were found in lipid levels between the SGA children, either examined as a group or subdivided according to catch-up growth, and matched AGA controls. The previous studies are not directly comparable with this study, as the children differed in age and pubertal development from those of the present study.

It is known that adiponectin may modulate the plasma lipid profile in an antiatherogenic manner, as associations with high HDL cholesterol and low triglyceride concentrations have been shown in adults (1). The present study demonstrated a positive correlation between adiponectin and $\operatorname{Lp}(\mathrm{a})$ only in children born SGA (but not in the AGA) and no relations with the other lipids. It was also observed that the most severely growth-restricted SGA children (birth weight $<3$ rd percentile) had higher $\operatorname{Lp}(\mathrm{a})$ levels than those between 3rd and 10th. It is difficult to determine the clinical significance of these findings.

Although intrauterine growth is a continuous process and the SGA classification is somewhat artificial, it appears that children at the low end of the birth weight range are prone to various metabolic aberrations. The severity of IUGR may be a factor to be taken into consideration when adiponectin, glucose and lipid metabolism are investigated in SGA children. This study indicates that prepubertal SGA born children have levels of serum adiponectin similar to or even higher than AGA children matched for age, sex, and BMI, despite the fact that the former are more insulin resistant. Further studies are required to assess whether the differences between AGA and SGA children observed in the pre-pubertal phase represent a long-term phenomenon.

\section{References}

1 Lihn AS, Pedersen SB \& Richelsen B. Adiponectin: action, regulation and association to insulin sensitivity. Obesity Reviews 20056 13-21.

2 Gil-Campos M, Canete R \& Gil A. Adiponectin, the missing link in insulin resistance and obesity. Clinical Nutrition 200423 963-974.

3 Hales CN \& Barker DJ. Type 2 (non-insulin-dependent) diabetes mellitus: the thrifty phenotype hypothesis. Diabetologia 199235 595-601.

4 Levy-Marchal C \& Jaquet D. Long-term metabolic consequences of being born small for gestational age. Pediatric Diabetes 20045 147-153.

5 Hattersley AT \& Tooke JE. The fetal insulin hypothesis: an alternative explanation of the association of low birthweight with diabetes and vascular disease. Lancet 1999353 1789-1792.

6 Morley R \& Dwyer T. Fetal origins of adult disease? Clinical and Experimental Pharmacology and Physiology $200128962-966$.

7 Cianfarani S, Martinez C, Maiorana A, Scire G, Spadoni GL \& Boemi S. Adiponectin levels are reduced in children born small for gestational age and are inversely related to postnatal catch-up growth. Journal of Clinical Endocrinology and Metabolism $2004 \mathbf{8 9}$ 1346-1351.

8 Lopez-Bermejo A, Casano-Sancho P, Fernadez-Real JM, Kihara S, Funahashi T, Rodriguez-Hierro F, Ricart W \& Ibanez L. Both intrauterine growth restriction and postnatal growth influence childhood serum concentrations of adiponectin. Clinical Endocrinology $200461544-552$.

9 Iniguez G, Soto N, Avila A, Salazar T, Ong K, Dunger D \& Mericq V. Adiponectin levels in the first 2 years of life in a prospective cohort: relations with weight gain, leptin levels and insulin sensitivity. Journal of Clinical Endocrinology and Metabolism 2004 89 5500-5503.

10 Karlberg J \& Albertsson-Wikland K. Growth in full-term small-forgestational-age infants: from birth to final height. Pediatric Research 199538 733-739.

11 Martin L, Woo J, Daniels S, Goodman E \& Dolan L. The relationships of adiponectin with insulin and lipids are strengthened with increasing adiposity. Journal of Clinical Endocrinology and Metabolism $2005904255-4259$. 
12 Matsubara M, Maruoca S \& Katayose S. Decreased plasma adiponectin concentration in women with dyslipidemia. Journal of Clinical Endocrinology and Metabolism $2002 \mathbf{8 7}$ 2764-2769.

13 Cianfarani S, Maiorana A, Geremia C, Scire G, Spadoni GL \& Germani D. Blood glucose concentrations are reduced in children born small for gestational age (SGA), and thyroid-stimulating hormone levels are increased in SGA with blunted postnatal catchup growth. Journal of Clinical Endocrinology and Metabolism 2003 88 2699-2705.

14 Thenola S, Martikainen A, Rahiala E, Herrgard E, Halonen P \& Voutilainen R. Serum lipid concentrations and growth characteristics in 12-year-old children born small for gestational age. Pediatric Research 200048 623-628.

15 Decsi T, Erhardt E, Marcus A, Burus I \& Molnar D. Plasma lipids, phospholipid fatty acids and indices of glycaemia in 10-year old children born as small-for-gestational-age or preterm infants. Acta Paediatrica 199988 500-504.

16 Pulzer F, Haase U, Kratzsch J, Richter V, Rassoul F, Kiess W \& Keller E. Lipoprotein (a) levels in formerly small-for-gestationalage children. Hormone Research 199952 241-246.

17 Nago N, Kayaba K, Hiroka J, Matsuo H, Goto T, Kario K, Tsutsuni A, Nakamura Y \& Igarashi M. Lipoprotein (a) levels in Japanese population: Influence of age and sex, and relation to atherosclerotic risk factors. American Journal of Epidemiology 1995 $141815-821$.

18 Geiss HC, Parhofer KG \& Schwandt P. Parameters of childhood obesity and their relationship to cardiovascular risk factors in healthy prepubescent children. International Journal of Obesity 200125 830-837.

19 Evagelidou E, Kiortsis D, Bairaktari E, Giapros V, Cholevas V, Tzallas C \& Andronikou S. Lipid profile, glucose homeostasis, blood pressure, and obesity-anthropometric markers in macrosomic offspring of nondiabetic mothers. Diabetes Care 200629 1197-1201.

20 Kiortsis DN, Milionis H, Bairaktari E \& Elisaf MS. Efficacy of combination of atorvastatin and micronised fenofibrate in the treatment of severe mixed hyrlipidemia. European Journal of Clinical Pharmacology 200056 631-635.

21 Friedewald WT, Levy RI \& Fredrickson DS. Estimation of the concentration of low-density lipoprotein cholesterol in plasma without use of preparative ultracentrifuge. Clinical Biochemistry $197218494-502$.

22 Gungor N, Saad R, Janosky J \& Arslanian S. Validation of surrogate estimates of insulin sensitivity and insulin secretion in children and adolescents. Journal of Pediatrics 2004144 47-55.

23 Altman D. Sample size Practical Statistics for Medical Research, pp. 456-460, London: Chapman and Hall, 1994.
24 Stefan N, Bunt J, Salbe A, Funahashi T, Matsuzawa Y \& Tataranni A. Plasma adiponectin concentrations in children: relationships with obesity and insulinemia. Journal of Clinical Endocrinology and Metabolism 200287 4652-4656.

25 Bach F, Saad R, Gungor N \& Arslanian S. Adiponectin in youth. Relationship to visceral adiposity, insulin sensitivity and $\beta$-cell function. Diabetes Care 200427 547-552.

26 Weyer C, Funahashi T, Tanaka S, Hotta K, Matsuzawa Y, Pratley RE \& Tataranni PA. Hypoadiponectinemia in obesity and type 2 diabetes: close association with insulin resistance and hypersulinemia. Journal of Clinical Endocrinology and Metabolism 200186 1930-1935.

27 Jaquet D, Deghmoun S, Chevenne D, Czernichow P \& LevyMarchal C. Low serum adiponectin levels in subjects born small for gestational age: impact on insulin sensitivity. International Journal of Obesity (London) 200630 83-87.

28 Hofman PL, Cutfield WS, Robinson EM, Bergman RN, Menon RK, Sperling MA \& Gluckman PD. Insulin resistance in short children with intrauterine growth retardation. Journal of Clinical Endocrinology and Metabolism 199782 402-406.

29 Cianfarani S, Germani D \& Branca F. Low birthweight and adult insulin resistance: the 'catch-up growth' hypothesis. Archives of Diseases in Childhood, Fetal and Neonatal Edition 199981 F71-F73.

30 Ong KK, Ahmed ML, Emmett PM, Preece MA, Dunger DB \& the Avon Longitudinal Study of Pregnancy and Childhood Study Team . Association between postnatal catch-up growth and obesity in childhood: prospective cohort study. British Medical Journal 2000 320 967-971.

31 Eriksson JG, Forsén T, Tuomilehto J, Winter PD, Osmond C \& Barker DJP. Catch-up growth in childhood and death from coronary heart disease: longitudinal study. British Medical Journal $1999318427-431$.

32 Rogers I \& EURO-BLCS Study Group, . The influence of birthweight and intrauterine environment on adiposity and fat distribution in later life. International Journal of Obesity and Related Metabolic Disorders 200327 755-777.

33 Malina RM, Katzamarzyk PT \& Beunen G. Birth weight and its relationship to size attained and relative fat distribution at 7 to 12 years of age. Obesity Research 19964 385-390.

34 Eisenmann J, Heelan K \& Welk G. Assessing body composition among 3 to 8 years old children. Anthropometry, BIA, and DXA. Obesity Research 200412 1633-1640.

Received 18 September 2006

Accepted 30 November 2006 